complex in vitro, which contains RNA polymerase as the principal protein attached to the DNA. When radioactive nucleoside triphosphates were added to the complex, synthesis of RNA was observed. This radioactive RNA had the high $G$ : $U$ ratio characteristic of ribosomal RNA, and hybridized efficiently to bulk DNA when the input level of RNA was low. Unlabelled $16 \mathrm{~S}$ and $23 \mathrm{~S}$ rRNAs competed efficiently with the synthesized material in hybridization. The unsurprising conclusion was that this DNA-protein complex was engaged chiefly in rRNA synthesis. Pettijohn et al. also referred to unpublished results showing that the RNAs released in the course of the synthesis had sedimentation coefficients of $23 \mathrm{~S}$ and $17 \mathrm{~S}$. From the amount of rRNA synthesized in the time the reaction continued, they calculate that as many as $100 \mathrm{RNA}$ polymerase molecules are attached to each 23S RNA cistron. This is close to the packing limit. Although these findings explain the very high rate of rRNA synthesis, the central problem is still the cause of the high rate of initiation of transcription of tRNA cistrons, by comparison with mRNAs such as the tryptophan operon.

Fuchs and Hanawalt (J. Mol. Biol., 52, 301; 1970) have described the isolation of a DNA-protein complex from $E$. coli. They believe that this is the growing point, or fork, which arises in the semi-conservative replication of DNA, where the two strands of the chromosomal DNA are parted, enabling the complementary strand to be synthesized on each of the original strands. Their secret lay in lysing the bacterial cells with a non-ionic detergent which did not dissociate the DNA-protein complex. The newly synthesized DNA in the neighbourhood of the growing points was specifically labelled with brief $(10-30 \mathrm{~s})$ pulses of radioactive thymine or thymidine immediately before lysis. The lysates were sonicated, and the labelled DNA-protein complex could be purified from the bulk DNA about 100 -fold by successive sucrose gradient centrifugation.

They investigated the complex by treating it with various enzymes, among other things. Both micrococcal nuclease and pronase caused rapid dissolution of the complex, as expected. Phospholipase, however, had no effect on stability. This is interesting, for it is commonly thought that the growing point is attached to the membrane of the bacterial cell. Nevertheless, it is possible that the growing point regions isolated by Fuchs and Hanawalt were detached from the membranes during lysis, while still retaining some structural integrity.

Perhaps their most significant finding was the negative result that there is virtually no DNA polymerase activity in the complex proteins, as judged by a standard assay for this enzyme. Furthermore, a mutant of $E$. coli described by De Lucia and Cairns which lacks active DNA polymerase nevertheless yields the same amount of the labelled complex as the wild type. It is difficult to avoid the conclusion already suggested by the viability of such mutants, that the DNA polymerase known and loved is not the enzyme of replication.

\title{
PROTOZOA
}

\section{Waves Caught by the Camera}

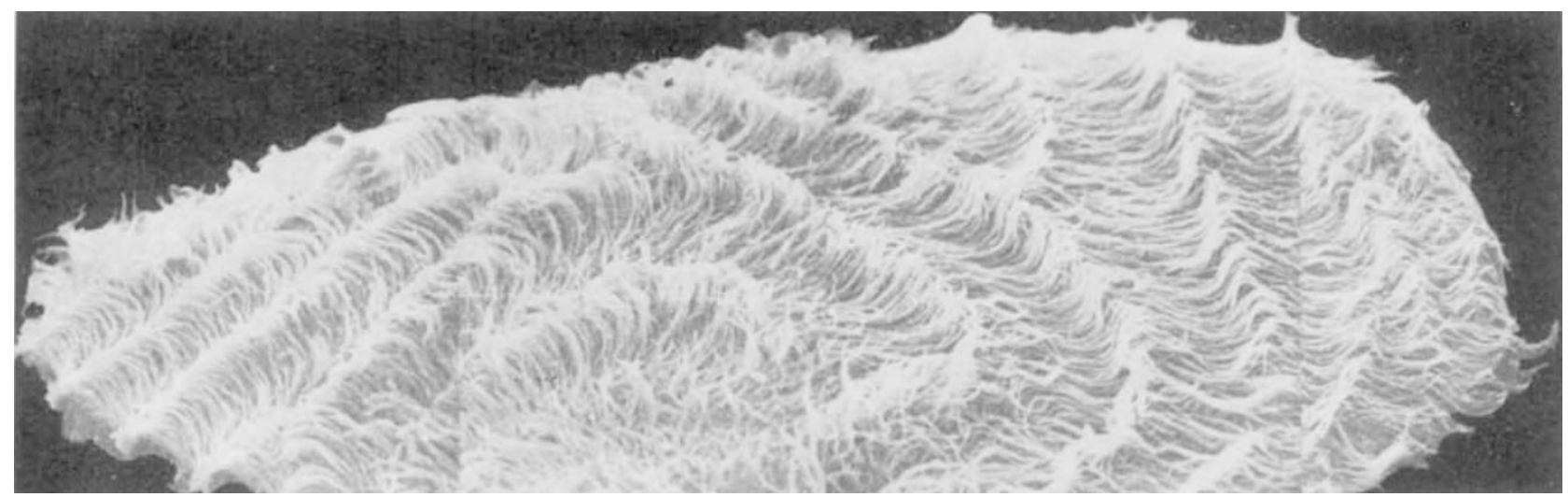

This is not a bath mat, but a composite electron micrograph of the protozoan Opalina, which has been fixed instantaneously and dried by the critical point method. The preparation of S. Tamm and G. Horridge (Proc. Roy. Soc., 175, 219; 1970) has preserved waves of movement passing through the cilia $(\times 3,000)$.

\section{FIBRES}

\section{Spinning a Yarn}

\section{from a Correspondent}

Developmexts in the fibre and textile industry seem to be coming thick and fast. New flame resistant textiles, fibres for reinforcing composites, and fibres from films were some of the topics for discussion at an international seminar, organized by the Shirley Insti- tute in Manchester from September 29 to October 1. Contributions concerned with new developments emphasized two approaches : the modification of existing fibres and the development of new fibres. Cotton and wool, two of the oldest fibres, can be modified to such an extent now that in some of their finished forms they must be regarded as "new" textiles. Dr H. R. Hardy (Courtaulds Ltd) described how viscose rayon, one of the oldest man-made fibres, has been developed into a range of new products. Among the most important of 